\title{
Home, School and Community Relations (9th Edition) By Carol Gestwicki (2017). Cengage Learning, Boston, MA (Book Review)
}

\author{
Jiryung Ahn \\ Associate Professor at Uiduk University \\ 261 Donghaedaero, Gangdongmyen, \\ Geyongju, Geyongbuk \\ South Korea
}

What is a good education for young children? How can we do for young children? Whenever I meet children and teachers, I always ask myself. Education could not be achieved by itself. It is a collaboration of all related things. As more families and teachers share the care of young children, it becomes obvious that disruptive tensions are more common than rare. Learning the skills of communicating effectively with families and teachers are matter in caring and educating young children. This is also very important part of teachers' preparation and training, even better professional development. Apparently, NAEYC (2018) suggests the standards of teacher preparation in regard to the 'Building family and community relationships.' It says that candidates prepare in early childhood programs understand that successful early childhood education depends upon partnerships with children's families and communities. They need to know about, understand, and value the importance and complex characteristics of children's families and communities. They use this understanding to create respectful, reciprocal relationships that support and empower families, and to involve all families in their children's development and learning. Then they suggest the key elements of this standard. That is, knowing about and understanding diverse family and community characteristics, supporting and engaging families and communities through respectful, reciprocal relationships, and involving families and communities in young children's development and learning.

The relationships with home, school and community are very crucial in the education. In this sense, we need to focus on effective relationship among home, school and community. For this purpose, we have to concentrate on this book and the content. The purpose of this book is to continue to raise some of the issues to sensitize teachers and parents. Then, we can understand the relationships of schools and homes in larger concepts incorporating into teachers' personal philosophies the idea that supporting the families. This new recognition toward the early childhood teachers, schools and programs are part of community enhance development and education of their children by creating partnerships and engagement. This book is covered with the themes of 'emphasis on diversity,' 'legislation recognizing families as partners,' 'full family engagement,' and 'continuing strengths of the text.' Then, it is consisted of four different sections and 15 chapters including diverse themes. The overview of the content is as following; Section 1 is about the introduction to families, that is the experience of parenting. Chapter 1. Introduces the subject by taking a look at two familieswith diverse experiences and unique needs. Chapter 2. takes in consideration with families in modern society. Ch 3. explains the roles of parent.

Section 2 explores teacher-family partnerships in early education. Ch. 4 examines various models of family involvement. Ch 5. explains benefits and barriers in teacher-family partnerships. Ch 6.Describesthe conditions that foundations of successful partnership and offers the examples of school where implements the partnership theory in their practice. Section 3 introduces the methods for developing partnerships. Ch 7. deals with good beginnings with parents and children. Ch 8. shows and explains an informal communication with families. Ch 9. explains about parentteacher conferences. Ch 10. introduces the role of families in the classroom. Ch 11. describes about parent education. Ch 12. shows the importance of making a village with teachers, families, and communication. Section 4 is related to the making a partnership work. Ch 13.deals with families from diverse backgrounds. Ch 14. Shows how we can work with families in particular circumstances. Finally, Ch 15. describes the way of resolving challenging attitudes and behaviors.

Each chapter begins with clearly defined learning objectives linked with the specific criteria from the NAEYC program standard. Therefore, it provides diverse examples and contribute the readers to understand easily. In each section, the author says the significance of relationships with family, school and community through the explanations of theory and suggestions of practices. In these senses, this book would be very helpful in preparation of teaching for young children. This could be a cornerstone of being and becoming a parent and teacher. It must be a good start for pre-service early childhood teachers' professional development.

\section{Reference}

NAEYC. (2018). https://www.naeyc.org/ 